JRR

\title{
Eye and visual function in traumatic brain injury
}

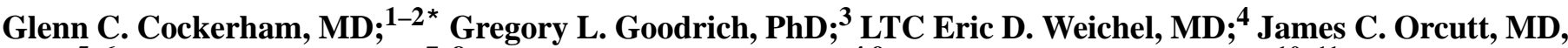 \\ PhD; ${ }^{5-6}$ Joseph F. Rizzo, MD; ${ }^{7-8}$ COL Kraig S. Bower, MD; ${ }^{4,9}$ Ronald A. Schuchard, PhD ${ }^{10-11}$ \\ ${ }^{1}$ Ophthalmology Section, Department of Veterans Affairs (VA) Palo Alto Health Care System, Palo Alto, CA; \\ ${ }^{2}$ Department of Ophthalmology, Stanford University, Stanford, CA; ${ }^{3}$ Psychology Service, VA Palo Alto Health Care \\ System, Palo Alto, CA; ${ }^{4}$ Ophthalmology Service, Walter Reed Army Medical Center, Washington, DC; ${ }^{5}$ Ophthalmology \\ Section, VA Puget Sound Health Care System, Seattle, WA; ${ }^{6}$ Department of Ophthalmology, University of Washington, \\ Seattle, WA; ${ }^{7}$ Center for Innovative Visual Restoration, VA Jamaica Plain, Boston, MA; ${ }^{8}$ Department of Ophthalmology, \\ Massachusetts Eye and Ear Infirmary, Boston, MA; ${ }^{9}$ Uniformed Services University of the Health Sciences, Bethesda, \\ MD; ${ }^{10}$ Research and Development Center of Excellence, Atlanta VA Medical Center, Atlanta, GA; ${ }^{11}$ Department of \\ Neurology, Emory University, Atlanta, GA
}

\begin{abstract}
Combat blast is an important cause of traumatic brain injury (TBI) in the Department of Veterans Affairs polytrauma population, whereas common causes of TBI in the civilian sector include motor vehicle accidents and falls. Known visual consequences of civilian TBI include compromised visual acuity, visual fields, and oculomotor function. The visual consequences of TBI related to blast remain largely unknown. Blast injury may include open globe (eye) injury, which is usually detected and managed early in the rehabilitation journey. The incidence, locations, and types of ocular damage in eyes without open globe injury after exposure to powerful blast have not been systematically studied. Initial reports and preliminary data suggest that binocular function, visual fields, and other aspects of visual function may be impaired after blast-related TBI, despite relatively normal visual acuity. Damage to the ocular tissues may occur from blunt trauma without rupture or penetration (closed globe injury). Possible areas for research are development of common taxonomy and assessment tools across services, surgical management, and outcomes for blast-related eye injury; the incidence, locations, and natural history of closed globe injury; binocular and visual function impairment; quality of life in affected servicemembers; pharmacological and visual therapies; and practice patterns for screening, management, and rehabilitation.
\end{abstract}

Key words: blast injury, blindness, eye trauma, oculomotor, quality of life, rehabilitation, traumatic brain injury, vision, visual disturbance, visual field.

\section{INTRODUCTION}

As of September 18, 2009, 31,501 U.S. servicemembers had been wounded by hostile action in Operation Iraqi Freedom (OIF) (www.defenselink.mil/news/casualty/pdf). A significant number received head injuries; from January 2003 to March 2006, 28 percent of patients evacuated to Walter Reed Army Medical Center (WRAMC) from theater received a diagnosis of traumatic brain injury (TBI). A report titled "Invisible wounds of war: Psychological and cognitive

\footnotetext{
Abbreviations: BCVA = best corrected visual acuity, COT = combat ocular trauma, DOD = Department of Defense, $\mathrm{MEB}=$ medical evaluation board, OEF = Operation Enduring Freedom, OIF = Operation Iraqi Freedom, PBI = primary blast injury, PNS = Polytrauma Network Site, PRC = Polytrauma Rehabilitation Center, QOL = quality of life, $\mathrm{TBI}=$ traumatic brain injury, VA = Department of Veterans Affairs, VFQ-25 = 25-Item Visual Functioning Questionnaire, WRAMC = Walter Reed Army Medical Center.

* Address all correspondence to Glenn C. Cockerham, MD; Ophthalmology Section 112-B1, Department of Veterans Affairs Palo Alto Health Care System, 3801 Miranda Avenue, Palo Alto, CA 94304; 650-858-3908; fax: 650-496-2502.

Email: glenn.cockerham@va.gov, cockerham@stanford.edu DOI:10.1682/JRRD.2008.08.0109
} 
injuries, their consequences, and services to assist recovery" published by the RAND Corporation in April 2008 estimated that, based on surveys of 1,965 servicemembers, 320,000 veterans may have incurred some level of TBI from action in Afghanistan or Iraq (http://veterans.rand.org). Powerful explosives are an increasingly common cause of TBI [1-9]. The majority of 797 severe eye injuries in OIF between 2003 and 2005 were caused by blast [10]. Of 88 patients with blast injuries from OIF and Operation Enduring Freedom (OEF) screened by the Defense and Veterans Brain Injury Center at WRAMC, 61 percent had TBI; more than half of these injuries were classified as moderate or severe (www.dvbic.org). TBI, particularly injury produced by blast events, has occurred at an unprecedented rate in Iraq and Afghanistan. Effective screening procedures to detect TBI in the absence of major physical injury have only recently been implemented; consequently, the extent of such injuries is currently unknown [11].

Blasts damage brain and ocular structures through a variety of mechanisms. Primary blast injury (PBI) is caused by the blast wave itself with changes of atmospheric pressure. Turbulence and cavitation create rebound and a secondary shock effect in soft tissues [12]. In animal studies within armored vehicles defeated with large warheads, PBI occurred in up to 20 percent of survivors [13]. Other injury mechanisms include secondary blast injury from flying objects, including metal casing or objects from the explosive device. Tertiary blast injury occurs when displaced victims impact a stationary object with rapid deceleration. Severe thermal burns may occur with high explosives. Combined injury refers to injury by any combination of these effects.

Kevlar body armor and helmets provide a level of protection against ballistic, projectile, and blast injury, but the face is unprotected. Polycarbonate eye armor (ballistic spectacles) also provide a measure of protection against projectiles, blast, and burn but have historically had a low level of acceptance among combat arms and armored personnel because of dust and sweat buildup and interference with quality and range of vision. As a consequence, the eye and ocular adnexa (eyelids and orbit) remain vulnerable to blast and ballistic injury. Of 207 severe eye injuries in a report of military casualties in OIF, 82 percent were caused by blast and blast fragmentation [14]. Eye injuries accounted for 13 percent (19/149) of all battlefield injuries seen at a combat support hospital during Operations Desert Shield and Desert Storm [15].

\section{MECHANISM OF INJURY: NEUROOPHTHALMIC CORRELATIONS}

\section{Pathophysiology}

Closed head injury associated with acceleration and deceleration may damage axons through stretch and shear forces, leading to diffuse axonal injury. Impaired axonal transport after injury may also lead to focal axonal swelling followed by axonal disconnection. Vision can be compromised because of injury to one or both optic nerves, impaired visual processing in diffuse brain injury, or limitation in eye movements because of dysfunction of cranial nerves [5]. TBI can also cause focal cerebral lesions, including subdural or epidural hematomas, subarachnoid or intracerebral hemorrhage, or cortical contusions. These injuries may compromise any of the neural pathways that subserve afferent or efferent visual function.

After traumatic breakdown of the blood-brain barrier, localized inflammation may occur. Cell death is initially necrotic, while apoptotic pathways mediate cell death later in the sequence [16]. The beta chemokine RANTES (regulated on activation, normal $\mathrm{T}$ cell expressed and secreted), which is constitutively expressed by different cells in the brain, is elevated after brain injury. This molecule encourages macrophage migration and activation and may correlate with severity of brain injury [17].

\section{Afferent Visual Injury}

Trauma can disrupt vision at many points along the afferent visual pathway, from the retina to the visual centers in the brain. Diffusion tensor imaging, a new technique capable of imaging white matter tracts within the brain, has the potential to analyze physiology of the afferent visual pathways [18-19]. Traumatic injury to the optic nerve, either from direct penetration or indirect injury from percussive forces, can cause severe blindness, with loss of both central vision and peripheral field. Traumatic optic nerve damage is not reversible by current therapies [20-21]. Severe cranial trauma can "split" the optic chiasm and produce a bitemporal hemianopia. Penetrating cranial injuries can also damage more posterior structures along the afferent visual pathway, usually at the level of the occipital cortex. Severe closed head injury may damage the white matter tracts that form the optic radiations, although this type of injury can be difficult to identify by clinical examination alone. More posterior injuries produce homonymous field defects. Severe bilateral injury to visual processing areas of the brain is extremely debilitating, because bilateral loss of both visual acuity and visual field occur. 


\section{Efferent Visual Injury}

Diplopia, or double vision, is a common symptom following TBI that damages the efferent visual pathways. Following trauma, dysfunction of cranial nerves III, IV, or VI may exist. In some cases, multiple nerves are involved. Diplopia, especially if it is present in primary position or down gaze, can severely reduce quality of life (QOL) and preclude continuation of active military duty, driving, or reading. A common, but less dramatic, consequence of closed head trauma is reduced ability to maintain binocular fusion, which may produce intermittent double vision through fixation instability. This type of problem usually produces subtle ocular motor findings and can be very difficult to distinguish from a phoria, a phenomenon commonly found on routine eye examination of nondisabled people. Horizontal phorias are typically benign and asymptomatic, although in some cases, a naturally occurring phoria will cause intermittent horizontal diplopia, usually with near vision, or more vague visual symptoms that can be hard to characterize. Vertical phorias are much more often the result of an identifiable neural problem. Damage to the brain can also produce permanent double vision because of the development of a skew deviation, in which the brain fibers that maintain the tonic alignment of the eyes are asymmetrically damaged and cause malpositioning of the eyes. Finally, damage to the peripheral or central vestibular system, including brainstem, cortex, and cerebellum, may cause nystagmus, blurred vision, or diplopia secondary to a skew deviation.

\section{COMBAT OCULAR TRAUMA AND TRAUMATIC BRAIN INJURY: MILITARY EXPERIENCE}

WRAMC is the largest military trauma center in the Department of Defense (DOD) and is the initial U.S. destination for the majority of combat injuries from OIF/ OEF. Weichel et al. treated 387 combat casualties with combat ocular trauma (COT) from OIF/OEF between March 2003 and October 2006 in the WRAMC Ophthalmology Department. There were 523 injured eyes within this group; 66 percent of servicemembers with COT also had TBI, of which 46 percent were associated with openglobe injuries and 16 percent were associated with penetrating head injury [22]. The majority of patients with COT had other injuries, most commonly TBI, facial injury, and limb injury. Patient median age was $28 \pm$ 7 years [22-23].
Hyphema (blood within the anterior chamber) and traumatic cataract were the most common findings in closedglobe injuries. Elevated intraocular pressure occurred in some patients. In most cases, the pressure was controlled with topical aqueous suppressants, but a tube shunt was occasionally necessary to control intraocular pressure. The majority (67\%) of eyes sustained adnexal or orbital injury. Burn injuries were present in some patients. However, the most severe burn patients are evacuated to the burn unit at Brooke Army Medical Center in San Antonio, Texas. Some patients with no light-perception vision required secondary enucleation following primary globe repair to avoid sympathetic ophthalmia. Other delayed definitive surgeries performed included orbital wall fracture repair and secondary eyelid reconstruction [22].

Traumatic optic neuropathy was a very common cause of best corrected visual acuity (BCVA) worse than $20 / 200$ [20]. Strabismus surgery was required in some patients to correct diplopia, typically when chronic diplopia occurred within the central $20^{\circ}$ of the visual field. TBI impacts COT in the outpatient follow-up period because patients with brain injury are frequently noncompliant with eye medications and appointments as a result of poor attention and short-term memory loss. During local or regional block ophthalmologic surgeries, patients with TBI move and talk excessively; laryngeal masked airway or general endotracheal anesthesia may lower the risk of surgical complications in this population.

\section{VISION AND TRAUMATIC BRAIN INJURY: DEPARTMENT OF VETERANS AFFAIRS EXPERIENCE}

In the study "Visual and ocular damage in blastinduced TBI," Cockerham and associates at Department of Veterans Affairs (VA) Palo Alto are currently evaluating veterans with TBI secondary to combat blast for QOL, visual function, and ocular damage. The mean age of the first 25 subjects enrolled was 28 years, with 23 males and 2 females. TBI severity levels and use and type of eyewear at injury were ascertained. QOL was determined by the 25-Item Visual Functioning Questionnaire (VFQ-25) [24], the Neurological-10 Supplement to the VFQ-25 [25], and Diplopia questionnaires [26]. QOL results will be compared with results from an agematched control group and published studies of patients with eye disease and will be serially followed. 
BCVA with Early Treatment Diabetic Retinopathy Study optotypes (Precision Vision; La Salle, Illinois) ranged from $20 / 10$ to $20 / 125$; 82 percent were $20 / 20$ or better. Despite normal visual acuities, some patients demonstrated abnormalities in other aspects of visual function, including spatial contrast sensitivity (measured by VectorVision; Greenville, Ohio), automated visual fields (measured by Humphrey Field Analyzer, Carl Zeiss Meditec; Dublin, California), and color discrimination (measured by D-15, Desaturated D-15 discs, Luneau; Chartres, France).

Complete ocular examinations revealed corneal injury, lens opacities, and/or angle recession closed globe injuries in some patients, including corneal injury. Retinal injuries included retinal detachment, choroidal ruptures, and intraretinal hemorrhage. Some of these eye injuries were asymptomatic and unsuspected by the patient. Neuroophthalmic examinations revealed fixation instability, gaze-evoked nystagmus in lateral gaze, abnormal vestibular ocular reflex, convergence insufficiency, and oculomotor palsies. Oculoplastic evaluation found facial and orbital fractures and scarring and ptosis of eyelids and eyebrows. Corneal endothelium, which is necessary for maintenance of a clear cornea and good vision, is known to be damaged by closed-globe injury and, conceptually, will be vulnerable to a blast wave. By specular microscopy, mean corneal endothelial density was reduced in veterans exposed to blast injury versus age- and refraction-matched controls. Severe reductions in endothelial counts were noted in some blast-injury patients on the side of the blast compared with the fellow eye. This study will continue for 3 years more to determine the natural history of visual consequences of blast injury.

Goodrich et al. described the functional visual characteristics of two groups of patients in the Palo Alto Polytrauma Rehabilitation Center (PRC) and Polytrauma Network Site (PNS) outpatient clinics [27-28]. The PRC population was an inpatient population of individuals who had sustained multiple and life-threatening injuries. The PNS population, in contrast, was an outpatient population able to live independently but diagnosed with mild TBI usually associated with a blast event. Severe visual impairment was present in one-third of the PRC patients, as measured by reduced visual acuity and/or field. Exposure to blast appeared to be associated with a markedly increased risk of severe visual impairment compared with all other causes of injury. The majority of both PRC and PNS patients, about three out of four, self-reported visual complaints that ranged from light sensitivity to total blindness, regardless of mechanism of injury. Although visual acuity and visual field examinations for both PRC and PNS patients without severe visual impairment were, on average, normal or near normal, clinical examination frequently noted binocular dysfunction, including accommodation and convergence insufficiency. These binocular problems may account for some of the self-reported vision complaints and contribute to reading and driving difficulties, as well as problems in performing activities of daily living. The PRC and PNS populations may represent the end points of severity of injury to the visual system, with the PRC group having the highest rate of visual impairment and visual dysfunction and the PNS group having a low rate of visual impairment but a high rate of visual dysfunction.

These Palo Alto studies are ongoing and several publications are in process. The Table provides data from these studies and amplifies our earlier reports. A control study of OIF/OEF patients without TBI has also begun. However, results are not yet available. The Palo Alto studies are attempting to review all PRC and PNS patient records or enroll all eligible patients, but eye examinations or screens are not always possible because of short length of stay and/ or changed appointments. The methodology was a retrospective review of standardized clinical eye examinations that have been previously described [27-28] and will not

\section{Table.}

Percentage of patients reporting or diagnosed with visual complaint. Palo Alto PRC inpatients $(n=108)$ had reading ability assessed with use of paragraph-length reading and comprehension materials (5th grade level), while Palo Alto PNS outpatients $(n=125)$ self-reported ability to perform sustained reading.

\begin{tabular}{lcc}
\hline \multicolumn{1}{c}{ Visual Complaint } & $\begin{array}{c}\text { PRC } \\
\text { Inpatient } \\
\text { (\%) }\end{array}$ & $\begin{array}{c}\text { PNS } \\
\text { Outpatient } \\
\text { (\%) }\end{array}$ \\
\hline Self-Report Visual Complaint & 75 & 75 \\
Blind/Severe Visual Impairment & 26 & $<2$ \\
Monocular & 10 & $<2$ \\
Strabismus & 32 & 8 \\
Accommodative Insufficiency & 31 & 47 \\
Convergence Insufficiency & 40 & 48 \\
Pursuit/Saccade Insufficiency & 29 & 23 \\
Fixation Insufficiency & 13 & 7 \\
Diplopia & 19 & 6 \\
Suppression & 11 & 5 \\
Visual Neglect & 5 & 0 \\
Reading Difficulty & 57 & 63 \\
$\quad$ (PRC assessed, PNS self-reported) & & \\
\hline PNS = Polytrauma Network Site, PRC = Polytrauma Rehabilitation Center. \\
\hline \hline
\end{tabular}


be covered in detail here. PRC patients receive a comprehensive eye examination conducted over 2 or more days. PNS patients receive an optometric screen and self-report questionnaire that is designed to uncover symptoms warranting a referral for additional services and requires about 45 minutes to complete.

Severe visual impairment (visual acuity of 20/100 or less) occurred in 1 of 4 PRC patients, and 1 in 10 was found to be monocular. In contrast, severe visual impairment or monocular status was infrequently diagnosed in the PNS population. Blast events accounted for 49.0 percent of injury in the PRC sample and 72.7 percent of injury in the PNS sample. Both sample populations exhibited high rates of accommodative, convergence, and pursuit/saccade insufficiency. The PRC sample was found to have twice the rate of fixation insufficiency, diplopia, and suppression as the PNS sample. One in twenty PRC, but none of the PNS, patients exhibited symptoms of visual neglect. As in previous studies, reading ability and comprehension of PRC patients were measured with use of paragraph-length materials, while reading ability was selfreported by PNS patients. More than half (57\%) of PRC patients had difficulty comprehending paragraph-length material. A similar percentage (63\%) of the PNS patients self-reported difficulty reading continuous text (Table).

In summary, the current data found that functional vision loss and/or visual dysfunction were common in the patient populations studied. Blast events were the most frequent cause of injury in both sample populations. PRC patients had higher rates of visual impairment or blindness than did the PNS patients. However, both groups exhibited high rates of binocular dysfunction. These findings are generally consistent with the existing literature on visual impairment/dysfunction associated with TBI [29-35]; however, differences in severity, mechanism of injury, assessment techniques, and other factors make comparisons difficult. On a functional level, the reading difficulties described for both the PRC and PNS populations are consistent with the visual impairment and/or visual dysfunction findings, but as previously stated, cognitive, attentional, or other factors may also contribute to these symptoms. Thus, the current data are descriptively important and provide valuable information for both programmatic and research development.

\section{REHABILITATIVE CARE}

Rehabilitative care focuses not just on ocular function but also on the overall function of the visual system. Cur- rent VA vision rehabilitation efforts vary to fit the needs of both populations (PRC and PNS) and the needs of individuals. Unfortunately, while vision injuries, deficits, and impairments appear to be common in these populations, there has been little systematic effort to understand the prevalence or impact of these conditions. Progress has been made in the development of treatments for a wide variety of visual deficits and losses that accompany TBI. Among the techniques currently used to address functional deficits related to various visual dysfunctions and losses are prisms [36], vision therapy [37-40], driving simulators [41-42], visuospatial training [43], and techniques to improve scanning and perception [39,44], as well as brain repair (plasticity), prostheses, and medications [44]. Techniques for addressing severe visual impairment are well documented throughout VA Blind Rehabilitation Services, and efforts are underway to adapt these to the polytrauma population both at local and national levels.

A service member must have a BCVA equal to or better than 20/800 in the injured eye with a BCVA of 20/20 in the fellow eye to remain on active duty without restrictions. Those not meeting the retention standards must undergo a medical evaluation board (MEB) assessment. A physical evaluation board then determines whether to allow continuation on active duty with a profile or medical retirement. servicemembers previously deployed in a war zone and medically discharged from the military are eligible for enrollment in the VA medical system. Service personnel with a BCVA of 20/200 or worse in the better eye are referred to VA Blind Rehabilitation Services. Admission criteria for polytrauma (multiple combat injuries) patients is any visual loss that impairs function; no specific visual acuity of field criteria are required. Soldiers are transferred from a DOD medical center to 1 of 10 VA rehabilitation units for an 8- to 16-week inpatient stay. Within this time frame, blinded or functionally visually impaired patients will learn the valuable skills needed to live independently. Upon completion of the rehabilitation program, the servicemember will return to complete the MEB process.

\section{CURRENT DEPARTMENT OF DEFENSE AND DEPARTMENT OF VETERANS AFFAIRS GUIDELINES FOR MANAGEMENT OF TRAUMATIC BRAIN INJURY}

Management of active-duty personnel and veterans with TBI is a continuum that ranges from a patient with 
mild TBI, whereby an active-duty member may return to his or her unit and continue on active duty, to a severely injured veteran with long-term cognitive and physical disabilities. How these patients are managed must be closely coordinated between DOD and VA providers. The DOD has a TBI center at WRAMC where assessment and treatment is provided. Some patients are discharged and move into the polytrauma system within the VA.

Availability of clinical information is critical in management of these patients, but little information is currently shared between DOD and VA providers. For example, information on the severity of the initial injury, duration of posttraumatic amnesia, associated physical injuries (polytrauma), current and past treatments, and current cognitive and visual disability is critical to effective and efficient care yet is not routinely available for all injured patients. This lack of information transfer is recognized as a barrier to care by VA and DOD providers, as well as the U.S. Congress. The 2008 National Defense Authorization Act established a DOD Vision Center of Excellence, which will be responsible for development and implementation of an Ocular Injury Registry, as well as education and research. Data in the registry will be viewable bidirectionally and updated by current providers.

\section{CONCLUSIONS}

Combat blast may damage the eye, adnexal tissues, visual pathways, or cortical processing areas through concussive or penetrating injuries. Combat trauma teams screen casualties for open globe injury and provide primary surgical management. Modern microsurgical techniques and prompt intervention near the site of injury may allow retention of useful vision in many instances. At WRAMC, common causes of BCVA worse than 20/200 were traumatic optic neuropathy, corneal scarring/decompensation, proliferative vitreoretinopathy, and primary enucleation/evisceration. Severely wounded polytrauma/ TBI casualties immediately enter into an intensive resuscitative and critical care situation. Those patients without obvious eye injury may have their first encounter with an eye care provider weeks or months after injury, after entry into a VA or civilian rehabilitation center. Combat veterans with blast-induced TBI who had no known eye injury, wore ballistic eye protection at the time of the blast injury, and had no ocular symptoms were found at the Palo Alto VA to have abnormalities in visual fields (often nonspe- cific), contrast sensitivity, and color discrimination. Many of those affected patients had normal or nearly normal high-contrast visual acuity, which calls into question the value of routine screening with an eye chart. Previously unsuspected ocular injuries were found in this population, including damage to the cornea, trabecular meshwork, lens, retina, and optic nerve. All of these injuries are potentially vision threatening and require long-term followup. Neuro-ophthalmic manifestations of TBI include visual field abnormalities, double vision, and nystagmus, which impair the ability to read, drive, and perform other activities of daily life.

Vision rehabilitation efforts to address the continuumof-care needs of troops and veterans are being developed. VA service providers and researchers will need to put in place service delivery plans backed by strong research components, which include control populations, prospective evaluations, and rigorous methodology for the assessment of functional vision. This approach will help ensure that the VA response to a unique healthcare need is both appropriate in scope and leads toward a systemwide standard of care.

\section{ACKNOWLEDGMENTS}

\section{Author Contributions:}

Study concept and design: G. C. Cockerham, G. L. Goodrich, E. D. Weichel.

Acquisition of data: G. C. Cockerham, G. L. Goodrich, E. D. Weichel.

Analysis and interpretation of data: G. C. Cockerham, G. L. Goodrich, E. D. Weichel.

Drafting of manuscript: G. C. Cockerham, G. L. Goodrich, E. D. Weichel, J. C. Orcutt, J. F. Rizzo, K. S. Bower, R. A. Schuchard. Critical revision of manuscript for important intellectual content: G. C. Cockerham, G. L. Goodrich, E. D. Weichel, J. C. Orcutt, J. F. Rizzo, K. S. Bower, R. A. Schuchard.

Statistical analysis: G. C. Cockerham, G. L. Goodrich, E. D. Weichel. Obtained funding: G. C. Cockerham, G. L. Goodrich, E. D. Weichel. Administrative, technical, or material support: G. C. Cockerham, G. L. Goodrich, E. D. Weichel.

Study supervision: G. C. Cockerham, G. L. Goodrich, E. D. Weichel.

Financial Disclosures: The authors have declared that no competing interests exist.

Funding/Support: This material was based in part on work supported by the VA through Merit Review Award C5018R and Quality Enhancement Research Initiative grant RRP 07-339.

Participant Follow-Up: Participants will be informed of the publication of this study at entry and follow-up. 


\section{REFERENCES}

1. Bhattacharjee Y. Neuroscience. Shell shock revisited: Solving the puzzle of blast trauma. Science. 2008;319(5862): 406-8. [PMID: 18218877] DOI:10.1126/science.319.5862.406

2. Hoge CW, McGurk D, Thomas JL, Cox AL, Engel CC, Castro CA. Mild traumatic brain injury in U.S. soldiers returning from Iraq. N Engl J Med. 2008;358(5):453-63. [PMID: 18234750$]$ DOI:10.1056/NEJMoa072972

3. Bochicchio GV, Lumpkins K, O’Connor J, Simard M, Schaub S, Conway A, Bochicchio K, Scalea TM. Blast injury in a civilian trauma setting is associated with a delay in diagnosis of traumatic brain injury. Am Surg. 2008;74(3): 267-70. [PMID: 18376697]

4. Grappling with traumatic brain injury. Lancet. 2007; 370(9603):1879. [PMID: 18068492]

DOI:10.1016/S0140-6736(07)61785-1

5. Taber KH, Warden DL, Hurley RA. Blast-related traumatic brain injury: What is known? J Neuropsychiatry Clin Neurosci. 2006;18(2):141-45. [PMID: 16720789]

DOI:10.1176/appi.neuropsych.18.2.141

6. Warden D. Military TBI during the Iraq and Afghanistan wars. J Head Trauma Rehabil. 2006;21(5):398-402. [PMID: 16983225] DOI:10.1097/00001199-200609000-00004

7. Okie S. Traumatic brain injury in the war zone. N Engl J Med. 2005;352(20):2043-47. [PMID: 15901856] DOI:10.1056/NEJMp058102

8. Cernak I, Savic J, Ignjatovic D, Jevtic M. Blast injury from explosive munitions. J Trauma. 1999;47(1):96-104.

[PMID: 10421194$]$

DOI:10.1097/00005373-199907000-00021

9. Trudeau DL, Anderson J, Hansen LM, Shagalov DN, Schmoller J, Nugent S, Barton S. Findings of mild traumatic brain injury in combat veterans with PTSD and a history of blast concussion. J Neuropsychiatry Clin Neurosci. 1998;10(3):308-13. [PMID: 9706538]

10. Thach AB, Johnson AJ, Carroll RB, Huchun A, Ainbinder DJ, Stutzman RD, Blaydon SM, Demartelaere SL, Mader TH, Slade CS, George RK, Ritchey JP, Barnes SD, Fannin LA. Severe eye injuries in the war in Iraq, 2003-2005. Ophthalmology. 2008;115(2):377-82. [PMID: 17904224] DOI:10.1016/j.ophtha.2007.04.032

11. U.S. Government Accountability Office (GAO). VA health care: Mild traumatic brain injury screening and evaluation implemented for OEF/OIF veterans, but challenges remain. Washington (DC): GAO; 2008 Feb. Report No.: GAO-08-276.

12. Stapczynski JS. Blast injuries. Ann Emerg Med. 1982; 11(12):687-94. [PMID: 7149365] DOI:10.1016/S0196-0644(82)80268-0
13. Phillips YY, Richmond DR. Primary blast injury and basic research: A brief history. In: Bellamy RF, Zajtchuk R, editors. Conventional warfare: Ballistics, blasts, and burn injuries. Washington (DC): Office of the Surgeon General of the U.S. Army; 1991. p. 221-40.

14. Mader TH, Carroll RD, Slade CS, George RK, Ritchey JP, Neville SP. Ocular war injuries of the Iraqi insurgency, January-September 2004. Ophthalmology. 2006;113(1):97-104. [PMID: 16290048$]$ DOI:10.1016/j.ophtha.2005.07.018

15. Heier JS, Enzenauer RW, Wintermeyer SF, Delaney M, LaPiana FP. Ocular injuries and diseases at a combat support hospital in support of Operations Desert Shield and Desert Storm. Arch Ophthalmol. 1993;111(6):795-98. [PMID: 8512480]

16. Ghirnikar RS, Lee YL, Eng LF. Inflammation in traumatic brain injury: Role of cytokines and chemokines. Neurochem Res. 1998;23(3):329-40. [PMID: 9482245] DOI:10.1023/A:1022453332560

17. Lumpkins K, Bochicchio GV, Zagol B, Ulloa K, Simard JM, Schaub S, Meyer W, Scalea T. Plasma levels of the beta chemokine regulated upon activation, normal $\mathrm{T}$ cell expressed, and secreted (RANTES) correlate with severe brain injury. J Trauma. 2008;64(2):358-61.

[PMID: 18301198] DOI:10.1097/TA.0b013e318160df9b

18. Ueki S, Fujii Y, Matsuzawa H, Takagi M, Abe H, Kwee IL, Nakada T. Assessment of axonal degeneration along the human visual pathway using diffusion trace analysis. Am J Ophthalmol. 2006;142(4):591-96. [PMID: 17011850] DOI:10.1016/j.ajo.2006.05.042

19. Schoth F, Burgel U, Dorsch R, Reinges MH, Krings T. Diffusion tensor imaging in acquired blind humans. Neurosci Lett. 2006;398(3):178-82. [PMID: 16466859] DOI:10.1016/j.neulet.2005.12.088

20. Steinsapir KD. Treatment of traumatic optic neuropathy with high-dose corticosteroid. J Neuroophthalmol. 2006; 26(1):65-67. [PMID: 16518171] DOI:10.1097/01.wno.0000204646.94991.68

21. Levin LA, Beck RW, Joseph MP, Seiff S, Kraker R. The treatment of traumatic neuropathy: The International Optic Nerve Trauma Study. Ophthalmology. 1999;106(7):1268-77. [PMID: 10406604] DOI:10.1016/S0161-6420(99)00707-1

22. Weichel ED, Colyer MH, Bautista C, Bower KS, French LM. Traumatic brain injury associated with combat ocular trauma. J Head Trauma Rehabil. 2009;24(1):41-50.

[PMID: 19158595]

DOI:10.1097/HTR.0b013e3181956ffd

23. Weichel ED, Colyer MH, Ludlow SE, Bower KS, Eiseman AS. Combat ocular trauma visual outcomes during Operations Iraqi and Enduring Freedom. Ophthalmology. 2008; 
115(12):2235-45. [PMID: 19041478$]$

DOI:10.1016/j.ophtha.2008.08.033

24. Mangione CM, Lee PP, Gutierrez PR, Spritzer K, Berry S, Hays RD; National Eye Institute Visual Function Questionnaire Field Test Investigators. Development of the 25-item National Eye Institute Visual Function Questionnaire. Arch Ophthalmol. 2001;119(7):1050-58. [PMID: 11448327]

25. Raphael BA, Galetta KM, Jacobs DA, Markowitz CE, Liu GT, Nano-Schiavi ML, Galetta SL, Maguire MG, Mangione CM, Globe DR, Balcer LH. Validation and test characteristics of a 10-item neuro-ophthalmic supplement to the NEI-VFQ-25. Am J Ophthalmol. 2006;142(6):1026-35. [PMID: 17046704] DOI:10.1016/j.ajo.2006.06.060

26. Holmes JM, Leske DA, Kupersmith MJ. New methods for quantifying diplopia. Ophthalmology. 2005;112(11):2035-39. [PMID: 16185766]

27. Goodrich GL, Kirby J, Cockerham G, Ingalla SP, Lew HL. Visual function in patients of a polytrauma rehabilitation center: A descriptive study. J Rehabil Res Dev. 2007;44(7): 929-36. [PMID: 18075950] DOI:10.1682/JRRD.2007.01.0003

28. Lew HL, Poole JH, Vanderploeg RD, Goodrich GL, Dekelboum S, Guillory SB, Sigford B, Cifu DX. Program development and defining characteristics of returning military in a VA Polytrauma Network Site. J Rehabil Res Dev. 2007; 44(7):1027-34. [PMID: 18075959] DOI:10.1682/JRRD.2007.05.0073

29. Schlageter K, Gray B, Hall K, Shaw R, Sammet R. Incidence and treatment of visual dysfunction in traumatic brain injury. Brain Inj. 1993;7(5):439-48. [PMID: 8401486] DOI:10.3109/02699059309029687

30. Ciuffreda KJ, Kapoor N, Rutner D, Suchoff IB, Han ME, Craig S. Occurrence of oculomotor dysfunctions in acquired brain injury: A retrospective analysis. Optometry. 2007;78(4):155-61. [PMID: 17400136]

DOI:10.1016/j.optm.2006.11.011

31. Ciuffreda KJ, Suchoff IB, Marrone MA, Ahmann EB. Oculomotor rehabilitation in traumatic brain-injured patients. J Behav Optom. 1996;7(2):31-38.

32. Starck T, Kenyon KR. Ocular trauma. In: Silverstone B, Lang MA, Rosenthal BP, Faye EE, editors. The Lighthouse handbook on vision impairment and vision rehabilitation. New York (NY): Oxford University Press; 2000. p. 143-74.

33. Stone SP, Halligan PW, Greenwood RJ. The incidence of neglect phenomena and related disorders in patients with an acute right or left hemisphere stroke. Age Ageing. 1993; 22(1):46-52. [PMID: 8438666]

DOI:10.1093/ageing/22.1.46

34. Padula WV, Argyris S. Post trauma vision syndrome and visual midline shift syndrome. NeuroRehabil. 1996;6(3):165-71.
35. Grosswasser Z, Cohen M, Blankstein E. Polytrauma associated with traumatic brain injury: Incidence, nature and impact on rehabilitation outcome. Brain Inj. 1990;4(2): 161-66. [PMID: 2331545] DOI:10.3109/02699059009026161

36. Peli E. Treating hemianopia using prisms to create peripheral diplopia. In: Stuen C, Arditi A, Horowitz A, Lang MA, Rosenthal B, Seidman K, editors. Vision rehabilitation: Assessment, intervention and outcomes. New York (NY): Swets \& Zeitlinger Publishers; 2000. p. 104-9.

37. Ciuffreda KJ, Rutner D, Kapoor N, Suchoff IB, Craig S, Han ME. Vision therapy for oculomotor dysfunctions in acquired brain injury: A retrospective analysis. Optometry. 2008;79(1):18-22. [PMID: 18156092] DOI:10.1016/j.optm.2007.10.004

38. Kasten E, Bunzenthal U, Müller-Oehring EM, Mueller I, Sabel BA. Vision restoration therapy does not benefit from costimulation: A pilot study. J Clin Exp Neuropsychol. 2007; 29(6):569-84. [PMID: 17691030]

DOI:10.1080/13803390600878919

39. Verlander D, Hayes A, McInnes JK, Liddle RJ, Liddle GW, Clarke GE, Russell M, Ferguson W, Walsh PG. Assessment of clients with visual spatial disorders: A pilot study. Vis Impair Res. 2000;2(3):129-42.

DOI:10.1076/vimr.2.3.129.4422

40. Klavora P, Warren M. Rehabilitation of visuomotor skills in poststroke patients using the Dynavision apparatus. Percept Mot Skills. 1998;86(1):23-30. [PMID: 9530706]

41. Lew HL, Poole JH, Lee EH, Jaffee DL, Huang HC, Brodd E. Predictive validity of driving-simulator assessments following traumatic brain injury: A preliminary study. Brain Inj. 2005;19(3):177-88. [PMID: 15832892] DOI:10.1080/02699050400017171

42. Klavora P, Heslegrave RJ, Young M. Driving skills in elderly persons with stroke: Comparison of two new assessment options. Arch Phys Med Rehabil. 2000;81(6):701-5. [PMID: 10857509]

43. Pizzamiglio L, Guariglia C, Antonucci G, Zoccolotti P. Development of a rehabilitative program for unilateral neglect. Restor Neurol Neurosci. 2006;24(4-6):337-45. [PMID: 17119308]

44. Warren M. A hierarchical model for evaluation and treatment of visual perceptual dysfunction in adult acquired brain injury, part 1. Am J Occup Ther. 1993;47(1):42-54. [PMID: 8418676]

Submitted for publication August 31, 2008. Accepted in revised form December 4, 2008. 